\title{
Analysis of Partial Shading Effects of Solar PV Module Configurations Using MATLAB/Simulink
}

\author{
Hoe-Gil Lee ${ }^{1, *}$, Jash N Shah², Panshul Tyagi ${ }^{2}$, Vigneshwar $\mathbf{M}^{2}$ \\ ${ }^{1}$ Department of Engineering and Computer Science, Tarleton State University, Box T-0390, Stephenville, TX 76402, USA \\ ${ }^{2}$ Department of Mechanical Engineering, Shiv Nadar University, District Gautam Buddha Nagar U.P. 2101 314, India \\ *Corresponding author: hlee@tarleton.edu
}

\begin{abstract}
Solar energy is an important aspect of renewable energy because we can easily obtain access to the source. The photovoltaic (PV) cell is the fundamental unit in the power conversion of the solar system. When the PV cells are exposed to partial shading as a result of a multitude of environmental conditions, the performance of the solar PV module is remarkably affected in terms of the efficiency of the system. In many cases, the PV arrays are shadowed, whether completely or partially, by passing clouds, neighboring buildings and towers, trees, or the shadow of one solar array falling on another. This study investigates the effects of partial shading on energy output of different configurations of solar PV modules. In this study, three different solar PV configurations are investigated: 1) Series 2) Parallel, and 3) Series-Parallel. All the considered PV configurations are analyzed using several possible scenarios of shading in order to evaluate their performances and to find a configuration that is comparatively less susceptible to electrical mismatches due to shadow problems. Owing to the practical difficulty of conducting experiments on varied array sizes, the proposed model also includes a general model of a PV module, which was implemented on MATLAB/Simulink and has been developed for any required array size, configuration and different shading patterns. This model is simple and especially useful to calculate the actual performances of the $\mathrm{PV}$ modules under various operating conditions.
\end{abstract}

Keywords: solar energy, photovoltaic cell, PV module, solar radiation, partial shading effects, MATLAB/Simulink

Cite This Article: Hoe-Gil Lee, Jash N Shah, Panshul Tyagi, and Vigneshwar M, "Analysis of Partial Shading Effects of Solar PV Module Configurations Using MATLAB/Simulink." American Journal of Energy Research, vol. 6, no. 1 (2018): 8-18. doi: 10.12691/ajer-6-1-2.

\section{Introduction}

With ever-increasing energy demand, a growing research thrust is on the development and utilization of renewable energy resources. Solar photovoltaic (PV) and solar thermal (parabolic trough, solar tower) are the technologies available that allow the capture of solar energy. In particular, because PV converts solar radiation directly to electricity, most solar power plants are developed based on PV technology. The increasing number of PV installations in the recent years serves to confirm the growing contribution of solar energy in power generation. However, a major challenge in using a PV source is to tackle its nonlinear output characteristics, which vary with temperature and solar insolation.

For some series-connected PV cells, even if some the cells are partially shaded, all the cells carry almost the same amount of current. While a small number of cells under shade produce less photocurrent, these cells are also forced to carry the same current as the other fully illuminated cells. Since a diode is reverse-biased, it does not conduct much of the current. At the same time, if the system is not appropriately considered under shading conditions, a hot-spot problem can negatively affect the performance of the solar PV cells, and the system can be damaged. In order to solve the stress on shaded solar PV cells, bypass diodes are required to the PV modules. In such a case, multiple peaks in power-voltage characteristics are observed under non-uniform illumination. Moreover, in some cases it is difficult to avoid partial shading of array due to the surrounding and environmental conditions, such as buildings, dust, bird droppings, and cloud cover throughout the day and in all seasons. This makes the study of partial shading of solar PV modules a key issue.

In recent years, the effects on partial shading on the solar PV array system performance have been widely discussed $[1,2,3,4]$. Like in H. S. Rauschenbusch's work [5], the power reduced due to a shadowed panel has already been studied. However, the power yield of PV modules is a function of different weather conditions, including solar irradiance [6], temperature [7], and configuration of PV array and partial shading [8]. It is important to consider all these parameters to determine the performance of a PV system under the various conditions of shading. Notably, Chin [8], in his work did not consider a detailed description of shading effects on the PV parameters. This paper aims to present a detailed study of various shading conditions on PV modules due to presence of clouds, trees and buildings.

R. Ramaprabha and B. L.Mathur [5] investigated the shading effects based on a required array's size, configuration, 
shading patterns, and a number of bypass diodes using MATLAB. Various configurations were studied in their research, and a modified configuration was developed that combined the advantages of the other configurations. A limitation to their research is that different random shading patterns were considered; hence, there was no consistency observed for the reason behind selecting particular shading patterns. L. Gao and R. A. Dougal stated that under shading conditions the parallel configuration should be dominant [9]. However, high output current at low voltage in a parallel configuration will have to be properly conditioned to the required level by using a suitable DC-DC converter. It is recommended to opt for other configurations. Therefore, in this report, various other configurations have been considered, and their performance under partial shading is evaluated. In their proposal, M. Abdulazeez and I. Iskender [10] studied the shading effect on series- and parallel-connected PV modules. The shading effect was artificially generated by covering parts of the module with partially transparent gelatin paper, reducing the incoming solar radiation by approximately $90 \%$. This comparative study examined series- and parallel-connected PV modules. When there is a reduction in insolation by $90 \%$, the temperature decreases, possibly resulting in the performance of the PV module to increase. The paper neglected to consider the effect of temperature when there is considerable reduction in irradiation.

In this paper, for different configuration types, generalized MATLAB/Simulink models have been developed. These are capable of simulating any number of modules connected in a series, parallel, or combination for any type of shading patterns. Possible scenarios of shading have been investigated as well as ways this possible shading can be utilized to comprehend and predict likely power output of different PV configurations from various shading patterns. For certain PV modules, the arrangement of the PV array dramatically contributes to changing the values of the maximum power subjected to partial shading conditions [11].

Research conducted by R.J. El-Khozondar and T. Suntio [12] concluded that the addition of the bypass diode becomes very important as the existence of the bypass diodes improves the solar PV performance, particularly in the cases where one of the modules is under fully shaded conditions. Therefore, the Simulink model developed for various configurations have the bypass diodes connected in anti-parallel with the PV module for improvement of the PV performance.

In this study, the main objective is to investigate the effects of partial shading caused by surrounding environmental conditions through the application of predefined configurations of the solar PV module system in series, parallel and series-parallel arrays. Furthermore, comparisons are made of their maximum output power for varying shading patterns based on the predefined layouts with possible scenarios. The study aims to find an equivalent electrical circuit model of the PV module when cells in the module are connected in series and parallel in order to analyze the characteristics of the module under uniform operating conditions.

\section{Modeling of Photovoltaic Array System Configurations}

In field testing, it is difficult to investigate the effects on partial shading because there are many barriers regarding cost, time and weather conditions. Also, it is challenging to uniformly measure the same level of intensity of shading under a number of different configurations of a shaded PV array system. Alternatively, it is convenient to carry out a simulation study with the help of a computer model. In this study, for different configuration types, generalized MATLAB/Simulink models have been developed and are capable of simulating any number of modules connected in series, parallel or combination for any type of shading patterns.

\subsection{Mathematical Modeling of a PV Cell and Module}

A PV module consists of a number of solar cells, which convert light into electricity. The solar cell mainly depends on a diode, a photocurrent $\left(I_{p h}\right)$, an internal resistor $\left(R_{s}\right)$, and a shunt resistor $\left(R_{s h}\right)$. Figure 1 shows a photovoltaic equivalent circuit of a single cell.

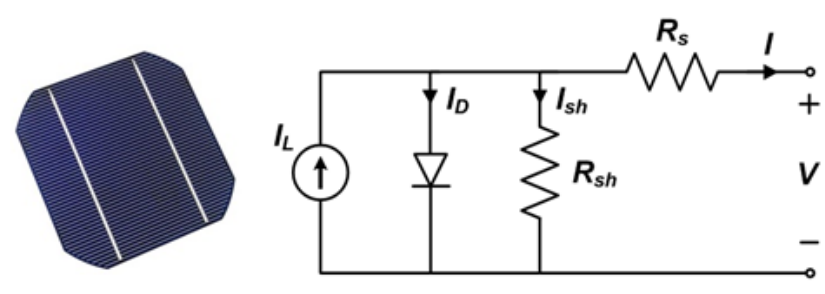

Figure 1. Photovoltaic equivalent circuit of a solar cell

When a PV module collects irradiance energy from the sun by individual solar cells, it is charged with electric energy. The output of electric energy depends on intensity of irradiance $\left(\frac{W}{m^{2}}\right)$, temperature $(\mathrm{K})$, material, design of the PV module, and the photocurrent $\left(I_{p h}\right)$ in series with the internal resistor $\left(R_{S}\right)$ and parallel with a shunt resistor $\left(R_{s h}\right)$, as shown in Figure 2.

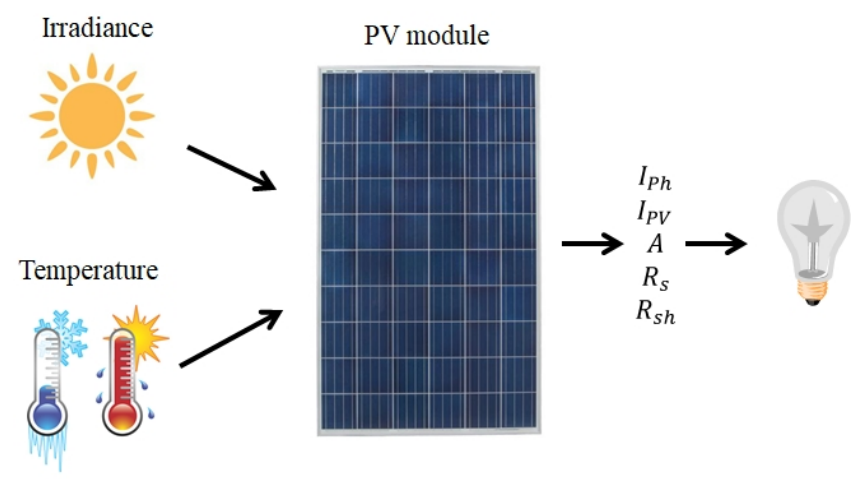

Figure 2. PV module performance with irradiance and temperature

The basic equation of the current at the terminal of the solar cell and the maximum power output are formulated. 
$[13,14]$ The photovoltaic panel can be mathematically modeled as:

- Basic mathematical equation of the output current (I) in Eq. (1)

$$
I=I_{p h}-I_{d}
$$

$I_{p h}$ is the photocurrent, $I_{d}$ is the diode current, which is related to the saturation current and is described by Eq. (2):

$$
I_{d}=I_{o}\left[\exp \left(\frac{V}{A \cdot N_{s} \cdot V_{T} \cdot a}\right)-1\right]
$$

where $V$ is the voltage applied to the diode, then $V_{T}$ can be expressed by the equation of $V_{T}=k \cdot \frac{T}{q} ; A$ is the diode ideality ranged between 1 and $2 ; N_{s}$ is the number of cells in a series for the output current; $a$ is the diode emission coefficient.

The photocurrent, $I_{p h}$, is generated from the incident solar irradiation and affected by the temperature $(T)$. It can be expressed by Eq. (3):

$$
I_{p h}=\frac{G}{G_{S T C}}\left(I_{p h, S T C}+K_{I}\left(T-T_{S T C}\right)\right)
$$

where $G_{S T C}\left(\frac{W}{m^{2}}\right)$ is the irradiation at STC; $I_{p h, S T C}$ is the current produced at STC; $K_{I}$ is the temperature coefficient of the short-circuit current.

The diode reverse leakage current, $I_{o}$, is influenced by the actual temperature and can be expressed in Eq. (4):

$$
I_{o}=\frac{I_{S C, S T C}+K_{I}\left(T-T_{S T C}\right)}{\exp \left(V_{O C, S T C}+K_{V} K_{I}\left(T-T_{S T C}\right)\right)-1}
$$

where $I_{S C, S T C}$ and $V_{O C, S T C}$ are the short-circuit current and open-circuit voltage at STC; $K_{V}$ is the temperature coefficient of the open-circuit voltage (V/Kelvin).

In the PV module, the short-circuit voltage $\left(I_{s c}\right)$ can be described when $V_{o}$ across the PV module is equal to zero and $I_{s c}$, as expressed in Eq. (5):

$$
I_{S C}=I_{P V}-I_{d}\left[\left(\exp \frac{I_{S C} R_{S}}{V_{T} \cdot a}\right)-1\right]-\frac{I_{S C} R_{S}}{R_{S H}} .
$$

- Maximum power point of a PV module in Eq. (6):

$$
I_{m p}=I_{P V}-I_{d}\left[\frac{V_{m p}+I_{m p} R_{S}}{V_{T} \cdot a}-1\right]-\frac{V_{m p}+I_{m p} R_{S}}{R_{S H}} \text {. }
$$

The maximum power, $P_{m}$, is calculated by $V_{m p} \times I_{m p}$ and described in Eq.(7):

$$
P_{m}=V_{m p}\left\{\begin{array}{l}
I_{P V}-I_{d}\left[\exp \frac{V_{m p}+I_{m p} R_{S}}{V_{T} a}-1\right] \\
-\frac{V_{m p}+I_{m p} R_{S}}{R_{S H}}
\end{array}\right\}
$$

where shunt resistance of the PV module is expressed in Eq.(8):

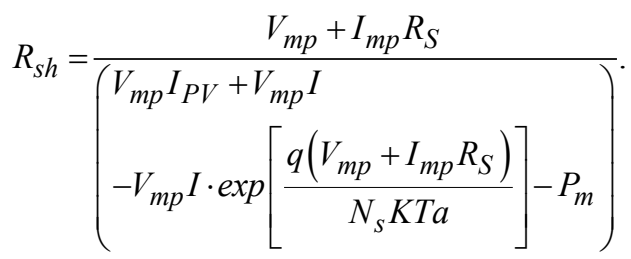

The $I-V$ and $P-V$ characteristics of the PV module operating at various temperatures and intensity of irradiance are determined.

\subsection{Solar PV Modules and Array System}

A solar PV panel module consists of a number of interconnected solar cells encapsulated into a stable panel module, and an array is constructed with a number of panel modules interconnected in series or parallel. A solar PV array system is comprised of the following components: (1) a number of solar cells, (2) a panel module connected in series, and (3) an array system that includes a charge control system and a storage system based on an AC/DC converter system for transmitting the electricity to a desired place, shown in Figure 3.

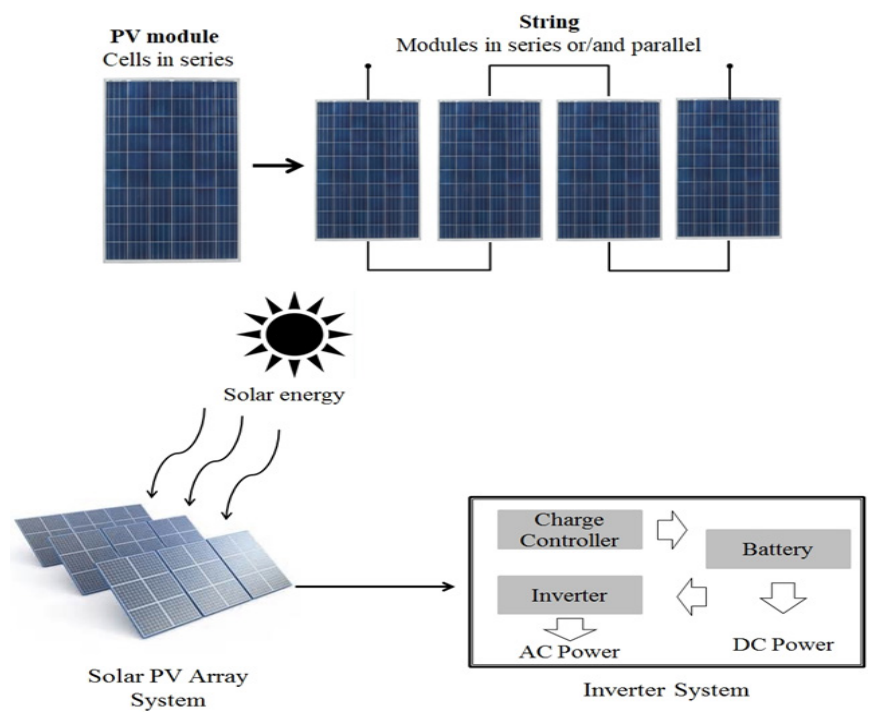

Figure 3. Solar PV array configuration and system 
Table 1. Electrical characteristics of MSX-60

\begin{tabular}{ccc}
\hline Parameter & Variable & Value \\
\hline Maximum Power & $P_{m}$ & $60 \mathrm{~W}$ \\
Voltage at $P_{m}$ & $V_{m p}$ & $17.1 \mathrm{~V}$ \\
Current at $P_{m}$ & $I_{m p}$ & $3.5 \mathrm{~A}$ \\
Open circuit Voltage & $V_{o c}$ & $21.1 \mathrm{~V}$ \\
Short Circuit Current & $I_{s c}$ & $3.8 \mathrm{~A}$ \\
Temperature coefficient of $I_{s c}$ & $K_{I}$ & $0.00065 \mathrm{~T} / \mathrm{A}$ \\
Temperature coefficient of $V_{o c}$ & $K_{V}$ & $0.008 \mathrm{~T} / \mathrm{V}$ \\
\hline
\end{tabular}

A commercial PV module is interconnected in series, and this standard is used to investigate the effects on maximum power points reached while under partial shading conditions. A single PV module is constructed from 36 PV cells derived from a multi-crystalline material. Table 1 shows the electrical characteristics of BP MSX-60 module used in this paper under standard test conditions (STC), indicating that irradiance $\mathrm{G}=1000 \mathrm{~W} / \mathrm{m}^{2}$, temperature $=25^{\circ} \mathrm{C}$, and $\mathrm{AM}=1.5$.

To compare the performance of different configurations under various possible scenarios, uniform operating data under standard test conditions (STC) has been used. These conditions define performance at an incident sunlight of $1000 \mathrm{~W} / \mathrm{m}^{2}$ and temperature of $25^{\circ} \mathrm{C}$.

This paper adopts the notions and characteristics of a simplified PV system that a single PV array system is interconnected with three individual PV modules of MSX60. The Simulink models for the various configurations in series, parallel, and series-parallel combination are shown below in Figure 4:

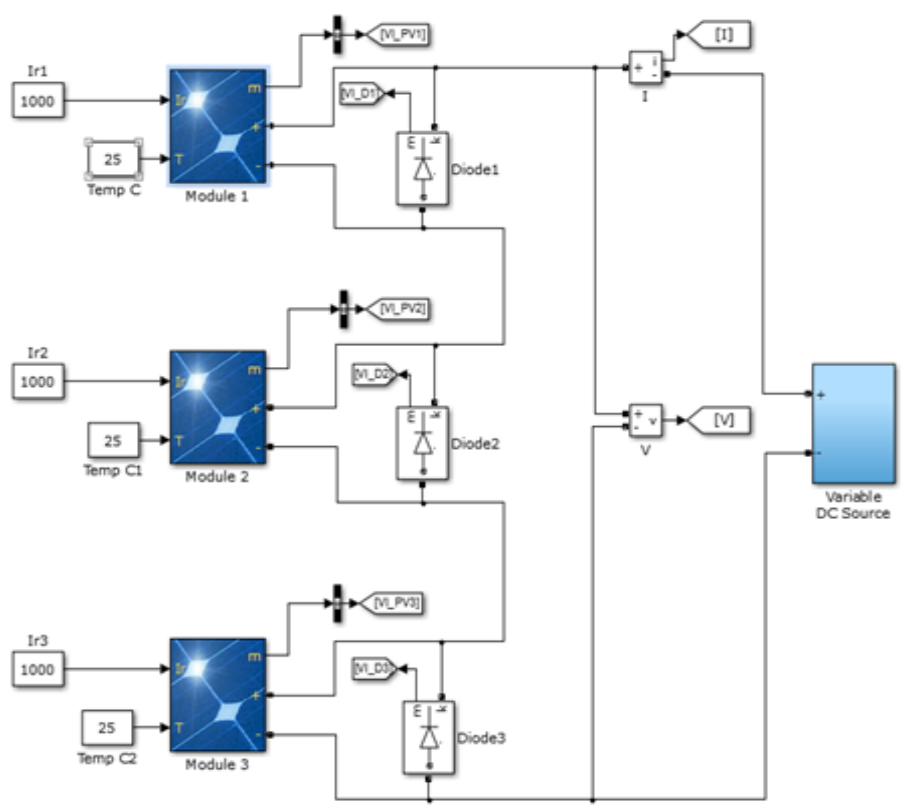

(a) PV module configurations connected in series

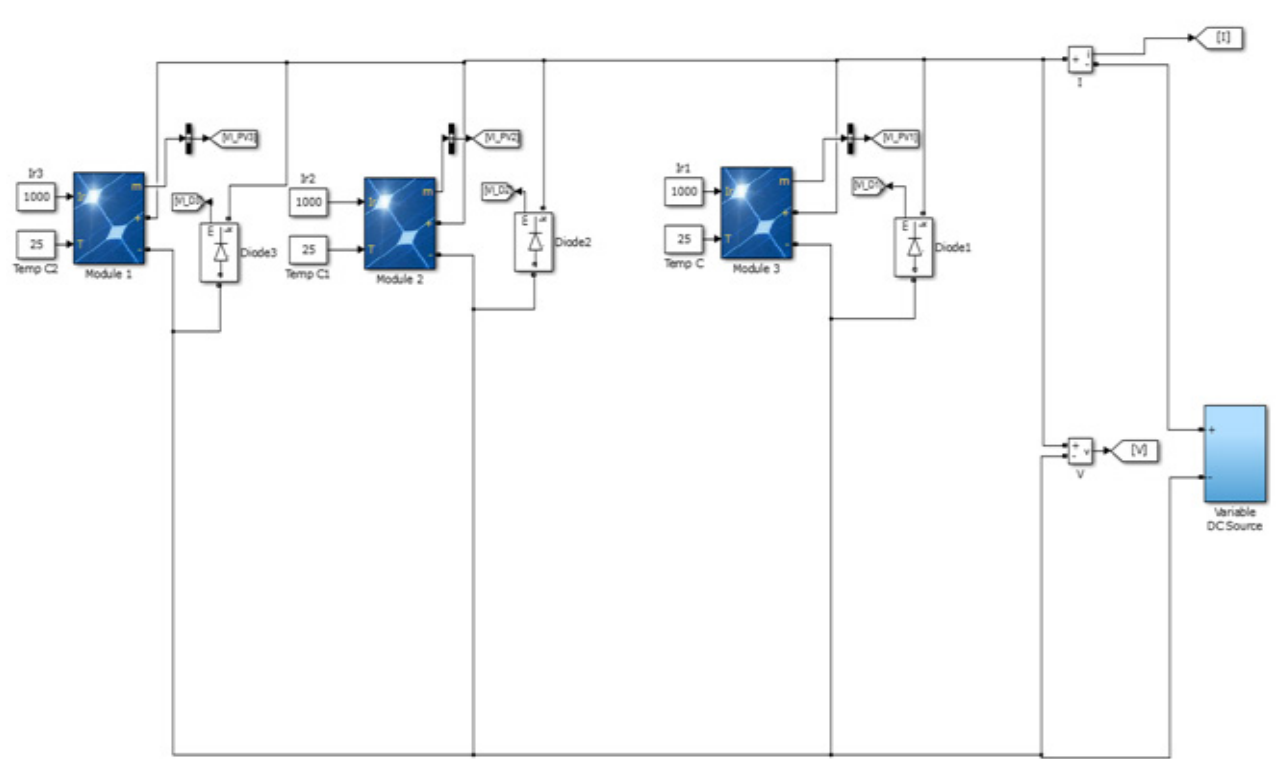

(b) PV module configurations connected in parallel

Figure 4. a,b 


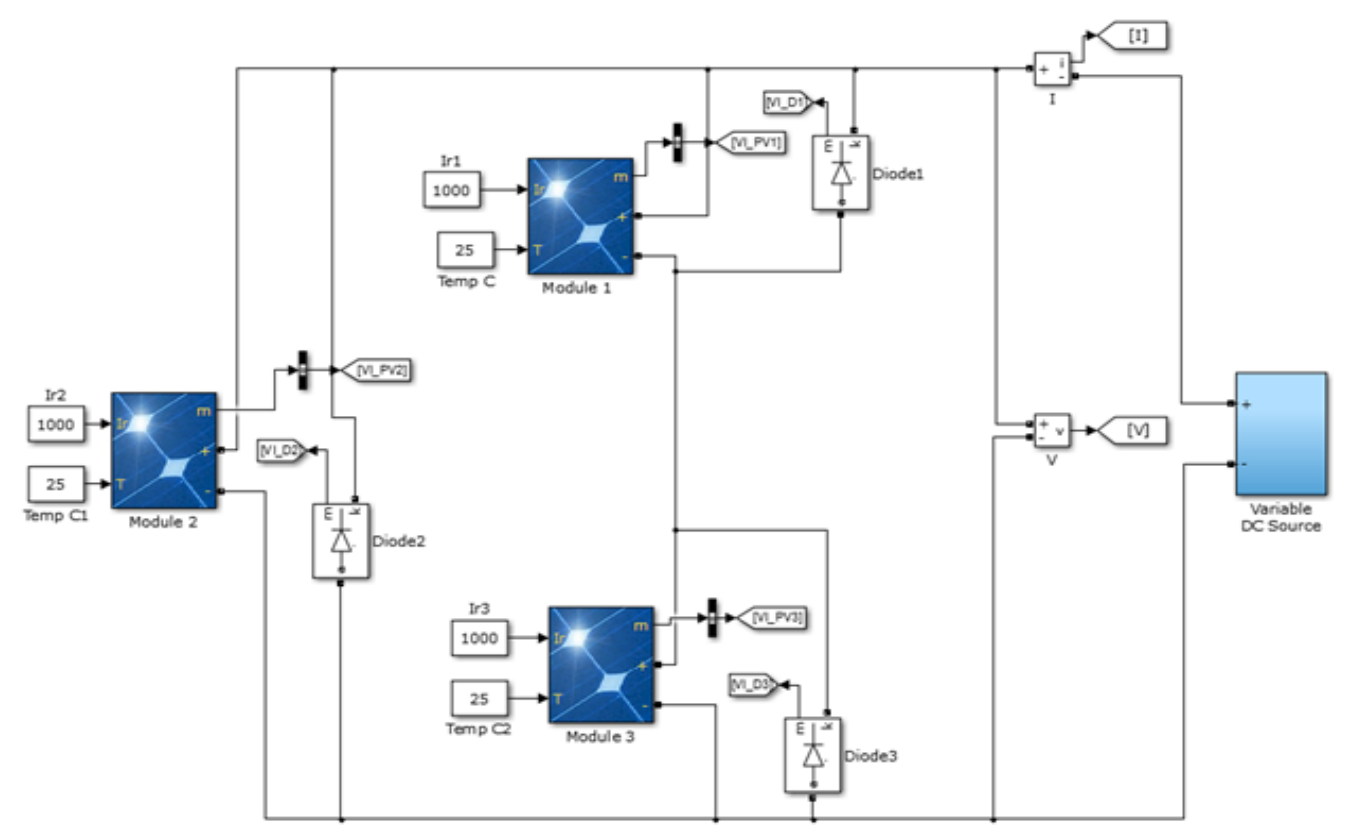

(c) PV module configurations connected in series-parallel (combination 1)

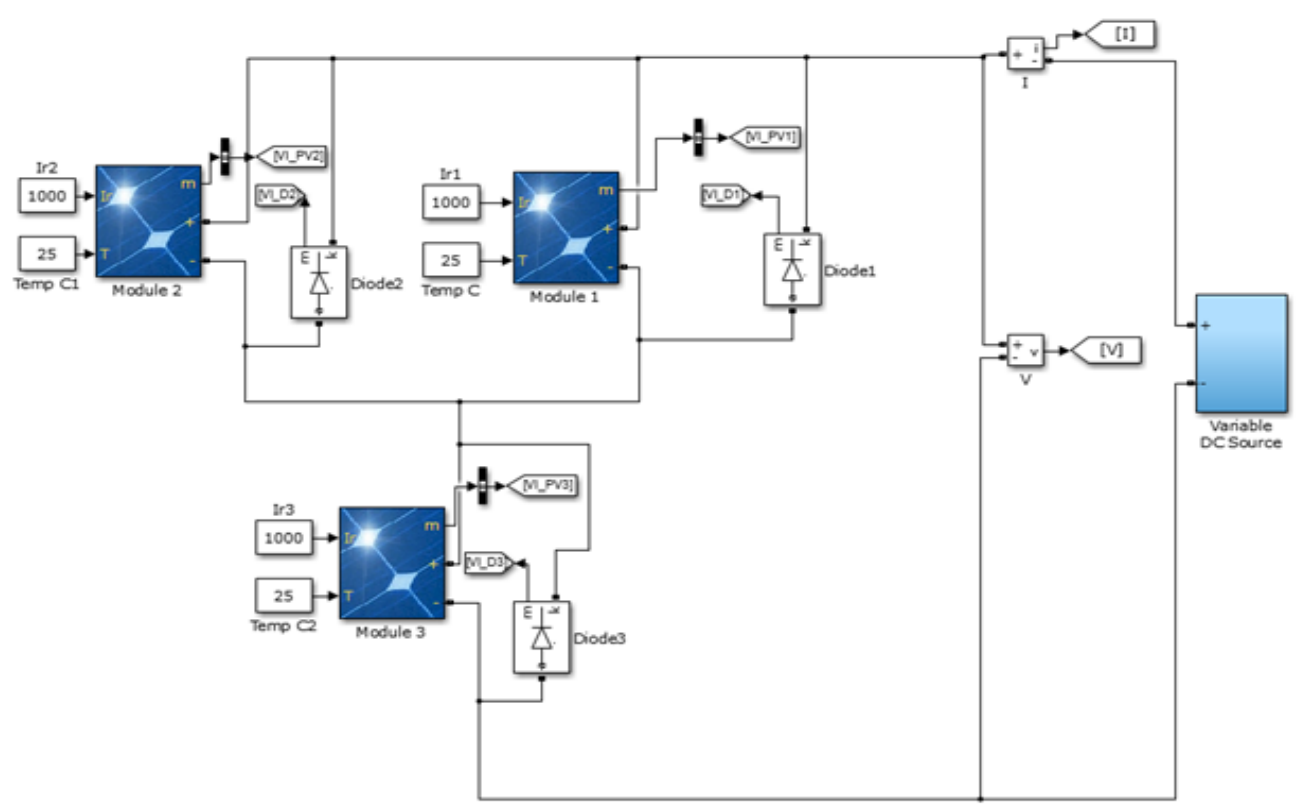

(d) PV module configurations connected in series-parallel (combination 2)

Figure 4. Simulink models with respect to PV array configurations

For the sake of comparison and simplicity, three modules have been used for the array configurations. Comparisons to M. Abdulazeez and I. Iskender's [10] work have been made to validate the model developed in this research work.

For comparing the various configurations, several unique possible scenarios have been studied. $I-V$ and $P-V$ graphs for each of these possible scenarios have been simulated, and values of maximum power, voltage, and current obtained from each case have been tabulated in this work.

\subsection{Case Studies}

The series, parallel and series-parallel configurations of modules have been simulated. To study and compare these configurations, a certain basis is required. In order to compare the different configurations, the following possible scenarios are proposed:

- Case I: One module is under partial shading effect, and the other is exposed to full irradiance.

- Case II: Two modules are under partial shading effect, and the other is exposed to full irradiance.

- Case III: All three modules are under partial shading effect.

Partial shading conditions of the PV array system affect power output. In this study, partial shading conditions are classified into four categories: 1) buildings, 2) snowy weather, 3) clouds, and 4) trees.

\subsubsection{Buildings}

C. Deline [15] proposed that the relative performance of one system versus the other could be averaged using a 
weighted average based on survey data that was collected for representative rooftop installations. There are three different shading conditions caused by buildings, and they were simulated by classifying levels of intensity: "light" shading (7\% annual irradiance reduction), "moderate" shading (15\%-19\% irradiance reduction), and "heavy" shading (25\% irradiance reduction). These shading conditions were to provide the basis for a weighted-average annual performance score of different solar PV systems. For this research, these three shading conditions have been used to compare the different solar PV array configurations. Table 2, Table 3 and Table 4 give a description on the various cases of shading caused by shade due to building over three PV modules with the corresponding irradiance values.

Table 2. Light shading condition with $7 \%$ irradiance reduction

\begin{tabular}{cccc}
\hline Case & $\begin{array}{c}\text { Module 1 } \\
\text { Irradiance }\left(\mathrm{W} / \mathrm{m}^{2}\right)\end{array}$ & $\begin{array}{c}\text { Module 2 } \\
\text { Irradiance }\left(\mathrm{W} / \mathrm{m}^{2}\right)\end{array}$ & $\begin{array}{c}\text { Module 3 } \\
\text { Irradiance }\left(\mathrm{W} / \mathrm{m}^{2}\right)\end{array}$ \\
\hline I & 1000 & 1000 & 930 \\
II & 1000 & 930 & 930 \\
III & 930 & 930 & 930 \\
\hline
\end{tabular}

Table 3. Moderate shading condition with $17 \%$ irradiance reduction

\begin{tabular}{cccc}
\hline Case & $\begin{array}{c}\text { Module 1 } \\
\text { Irradiance }\left(\mathrm{W} / \mathrm{m}^{2}\right)\end{array}$ & $\begin{array}{c}\text { Module 2 } \\
\text { Irradiance }\left(\mathrm{W} / \mathrm{m}^{2}\right)\end{array}$ & $\begin{array}{c}\text { Module 3 } \\
\text { Irradiance }\left(\mathrm{W} / \mathrm{m}^{2}\right)\end{array}$ \\
\hline I & 1000 & 1000 & 830 \\
II & 1000 & 830 & 830 \\
III & 830 & 830 & 830 \\
\hline
\end{tabular}

Table 4. Heavy Shading condition with $25 \%$ irradiance reduction

\begin{tabular}{cccc}
\hline Case & $\begin{array}{c}\text { Module } 1 \\
\text { Irradiance }\left(\mathrm{W} / \mathrm{m}^{2}\right)\end{array}$ & $\begin{array}{c}\text { Module 2 } \\
\text { Irradiance }\left(\mathrm{W} / \mathrm{m}^{2}\right)\end{array}$ & $\begin{array}{c}\text { Module 3 } \\
\text { Irradiance }\left(\mathrm{W} / \mathrm{m}^{2}\right)\end{array}$ \\
\hline I & 1000 & 1000 & 750 \\
II & 1000 & 750 & 750 \\
III & 750 & 750 & 750 \\
\hline
\end{tabular}

\subsubsection{Snowy Weather}

In order to identify the relationship between a lowperforming module and snowy weather or dust, historical climate condition data from a third party reference was collected. R. French [16] uses the solar PV performance ratio (PR), which is a measure of PV module output at a given incident power from sunlight, as an indicator of a modules' working effectiveness. The PR of the modules was small or equal to zero even when irradiance was not very low, which indicates that the module may experience snow coverage. Historical climate condition data from a third party website was collected for evaluating the performance. Low PR appears only during or after snow or fog-snow days. For this research, we are taking into account the average PR value, which is $0.4-0.3$. With this, the amount of irradiance that is incident on the PV module can be calculated. It is also worth considering the fact that snowy weather is marked with a decrease in temperature. For this research, the average temperatures of the months of January, February and March in Cleveland, Ohio were used. The average temperature collected from a third party website was found to be $4.26^{\circ} \mathrm{C}$ for those 3 months in Cleveland. Table 5 describes values of irradiance when the PV modules are covered with snow.
Table 5. Effect of Snow on PV modules

\begin{tabular}{cccc}
\hline Description & $\begin{array}{c}\text { Module 1 } \\
\text { Irradiance } \\
\left(\mathrm{W} / \mathrm{m}^{2}\right)\end{array}$ & $\begin{array}{c}\text { Module 2 } \\
\text { Irradiance } \\
\left(\mathrm{W} / \mathrm{m}^{2}\right)\end{array}$ & $\begin{array}{c}\text { Module 3 } \\
\text { Irradiance } \\
\left(\mathrm{W} / \mathrm{m}^{2}\right)\end{array}$ \\
\hline $\begin{array}{c}\text { When all three modules are } \\
\text { under snow }\end{array}$ & 400 & 400 & 400 \\
\hline
\end{tabular}

\subsubsection{Clouds}

P. Burgess [17] discusses how solar irradiation intensity varies with cloud cover and different seasons. According to Burgess, there is around $25 \%$ loss even when the sky is clear, and this is due to scattering of light and other phenomena. It was stated that these losses may be quantified as high as $75 \%$ when the cloud cover density is heavy. For instance, during a dark, thundery sky, only 5 to $10 \%$ of the potential radiation is received. In this work, the effect of cloud cover causing partial shading on the PV array has been considered. Specifically, high cloud density eventually leading to partial or full shading on the PV module has been considered. Seasonal data of New Delhi, India, a city that has an average temperature of $15^{\circ} \mathrm{C}$ during winters, was examined. Table 6 indicates the values of irradiance when the PV modules are covered with clouds.

Table 6. Heavy cloud condition with $50 \%$ irradiance reduction

\begin{tabular}{cccc}
\hline Case & $\begin{array}{c}\text { Module 1 } \\
\text { Irradiance } \\
\left(\mathrm{W} / \mathrm{m}^{2}\right)\end{array}$ & $\begin{array}{c}\text { Module } 2 \\
\text { Irradiance } \\
\left(\mathrm{W} / \mathrm{m}^{2}\right)\end{array}$ & $\begin{array}{c}\text { Module 3 } \\
\text { Irradiance } \\
\left(\mathrm{W} / \mathrm{m}^{2}\right)\end{array}$ \\
\hline I & 1000 & 1000 & 500 \\
II & 1000 & 500 & 500 \\
III & 500 & 500 & 500 \\
\hline
\end{tabular}

Table 7 (given below) describes the various cases of shade possible from heavy rains. For this study, seasonal data of New Delhi, India from a third party website was collected for consistency. In instances of rain when there is little or no trace of sun, minimum irradiance is captured by the PV modules. Therefore, there can be a drastic reduction in irradiance values. The average temperature of New Delhi was estimated to be $32.5^{\circ} \mathrm{C}$ during heavy rain season.

Table 7. Heavy rains condition with $90 \%$ irradiance reduction

\begin{tabular}{cccc}
\hline Case & $\begin{array}{c}\text { Module 1 } \\
\text { Irradiance }\left(\mathrm{W} / \mathrm{m}^{2}\right)\end{array}$ & $\begin{array}{c}\text { Module 2 } \\
\text { Irradiance }\left(\mathrm{W} / \mathrm{m}^{2}\right)\end{array}$ & $\begin{array}{c}\text { Module 3 } \\
\text { Irradiance }\left(\mathrm{W} / \mathrm{m}^{2}\right)\end{array}$ \\
\hline I & 1000 & 1000 & 100 \\
II & 1000 & 100 & 100 \\
III & 100 & 100 & 100 \\
\hline
\end{tabular}

\subsubsection{Trees}

G.M. Heisler [18] carried out research on how the effect of individual trees would be on the irradiance incident on a PV array. The significance of the irradiance reductions for a PV array was tested by using physical models of representative tree crowns (similar to maple) and a PV array to evaluate shadow patterns. The paper concluded that, on clear days, the average reduction in the shade of trees in leaf ranged from $65 \%$ to $85 \%$.

The following research and results were obtained during analysis and experiments conducted in U.S.A. Table 8 describes values of irradiance when PV modules 
are under the effects of shading conditions caused by the trees.

Table 8. Effect of tree-blockage condition with $50 \%$ irradiance reduction

\begin{tabular}{cccc}
\hline Case & $\begin{array}{c}\text { Module 1 } \\
\text { Irradiance }\left(\mathrm{W} / \mathrm{m}^{2}\right)\end{array}$ & $\begin{array}{c}\text { Module 2 } \\
\text { Irradiance }\left(\mathrm{W} / \mathrm{m}^{2}\right)\end{array}$ & $\begin{array}{c}\text { Module 3 } \\
\text { Irradiance }\left(\mathrm{W} / \mathrm{m}^{2}\right)\end{array}$ \\
\hline I & 1000 & 1000 & 250 \\
II & 1000 & 250 & 250 \\
III & 250 & 250 & 250 \\
\hline
\end{tabular}

\section{Numerical Results}

In this section, solar PV module $I-V$ characteristics are investigated to find maximum performance with respect to various configurations of solar PV modules interconnected in series, parallel, and a combination of serial-parallel strings. In order to compare the power output of the different configurations, the possible scenarios are shown as Case I, II, and III.

\subsection{PV Module Characteristic Curves When Cells Are Connected in Series}

The characteristic $I-V$ curve indicates that there are two regions in the curve: one is the current source region and another is the voltage source region. In the voltage source region (in the right side of the curve), the internal impedance is low, and in the current source region (in the left side of the curve), the impedance is high. When the
$I-V$ characteristic and effects of both factors are considered for evaluating performance of the solar PV array system, irradiance temperature plays a key role in designing the PV system. Whereas irradiance affects the power output, temperature mainly affects the terminal voltage.

The results of the performance of the PV module in series and parallel using MATLAB/Simulink are shown in Table 9 .

Table 9. Performance evaluation when cells are connected in series and parallel in terms of maximum power, voltage, and current.

\begin{tabular}{cccc}
\hline Configuration & $\begin{array}{c}\text { Max. Power } \\
(\mathrm{W})\end{array}$ & $\begin{array}{c}\text { Max. Current } \\
(\mathrm{A})\end{array}$ & $\begin{array}{c}\text { Max. Voltage } \\
(\mathrm{V})\end{array}$ \\
\hline Series & 63.2982 & 3.5561 & 17.800 \\
Parallel & 40.2551 & 125.7971 & 0.3200 \\
\hline
\end{tabular}

From the above table, it can be interpreted that cells provide higher power output when connected in series in a PV module. Therefore, it can be assumed that commercial PV cells and modules are predominantly connected in series.

\subsection{Performance of the Various System Configurations}

Performance of various configurations under different shading scenarios has been discussed. The simulation results were obtained by using the model that was developed for various configurations using Simulink.

In Table 10, the peak power, voltage, and current for the three configurations under different possible scenarios has been tabulated and compared.

Table 10. Scenario 1: Comparison of the various configurations under shading due to buildings

\begin{tabular}{|c|c|c|c|c|c|}
\hline Scenario & Case & Configuration & Max. Power (W) & Max. Current (A) & Max. Voltage (V) \\
\hline \multirow{9}{*}{ a) Size of Shade due to Building (Light Shading) } & \multirow{3}{*}{ I } & Series & 173.4 & 3.345 & 51.84 \\
\hline & & Parallel & 175.4 & 10.25 & 17.11 \\
\hline & & Series-Parallel & 130.2 & 3.604 & 36.12 \\
\hline & \multirow{3}{*}{ II } & Series & 170 & 3.291 & 51.65 \\
\hline & & Parallel & 171.3 & 10.01 & 17.11 \\
\hline & & Series-Parallel & 130 & 3.604 & 36.06 \\
\hline & \multirow{3}{*}{ III } & Series & 167.2 & 3.256 & 51.36 \\
\hline & & Parallel & 167.2 & 9.771 & 17.11 \\
\hline & & Series-Parallel & 121.4 & 3.354 & 36.19 \\
\hline \multirow{9}{*}{ b) Size of Shade due to Building (Moderate Shading) } & \multirow{3}{*}{ I. } & Series & 159.7 & 3.011 & 53.05 \\
\hline & & Parallel & 169.5 & 9.904 & 17.11 \\
\hline & & Series-Parallel & 129.8 & 3.605 & 36.02 \\
\hline & \multirow{3}{*}{ II } & Series & 154.1 & 2.955 & 52.14 \\
\hline & & Parallel & 159.5 & 9.31 & 17.13 \\
\hline & & Series-Parallel & 129.1 & 3.602 & 35.85 \\
\hline & \multirow{3}{*}{ III } & Series & 149.5 & 2.907 & 51.44 \\
\hline & & Parallel & 149.5 & 8.717 & 17.15 \\
\hline & & Series-Parallel & 108.4 & 2.994 & 36.19 \\
\hline \multirow{9}{*}{ c) Size of Shade due to Building (Heavy Shading) } & \multirow{3}{*}{ I } & Series & 146.8 & 2.725 & 53.87 \\
\hline & & Parallel & 164.7 & 9.626 & 17.11 \\
\hline & & Series-Parallel & 129.5 & 3.604 & 35.93 \\
\hline & \multirow{3}{*}{ II } & Series & 140.4 & 2.665 & 52.69 \\
\hline & & Parallel & 150.0 & 8.755 & 17.13 \\
\hline & & Series-Parallel & 128.3 & 3.601 & 35.62 \\
\hline & \multirow{3}{*}{ III } & Series & 135.3 & 2.628 & 51.46 \\
\hline & & Parallel & 135.3 & 7.886 & 17.15 \\
\hline & & Series-Parallel & 97.88 & 2.706 & 36.17 \\
\hline
\end{tabular}


It is observed that for any configuration, as the number of modules under shading increases, the power decreases, confirming that shading has a a negative effect on the power output of an array. It is also observed that for each of the three cases of shading (light, medium and heavy shading), the parallel configuration gives the best performance. It is worth noting that parallel configuration gives better results only when a part of an array is shaded while in cases of uniform shading(where all the modules are shaded), parallel and series configuration give the same output. Figure 5 shows variations with respect to levels of partial shadings in series, parallel, and series-parallel.

Table 11 shows the results of the maximum power output with maximum current and voltage for partial shading effect from snow with respect to the various PV module configurations.

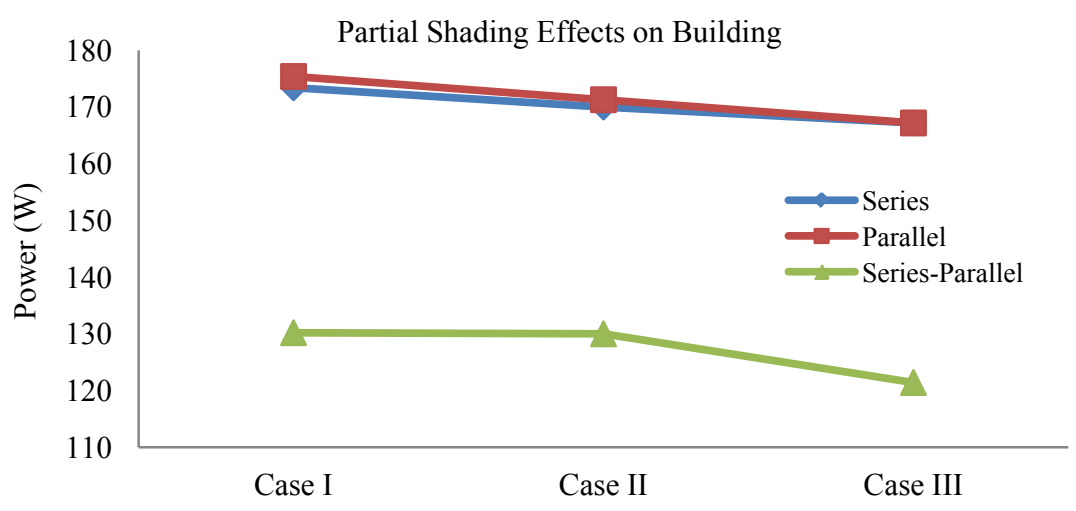

(a) Level of light partial shading on building

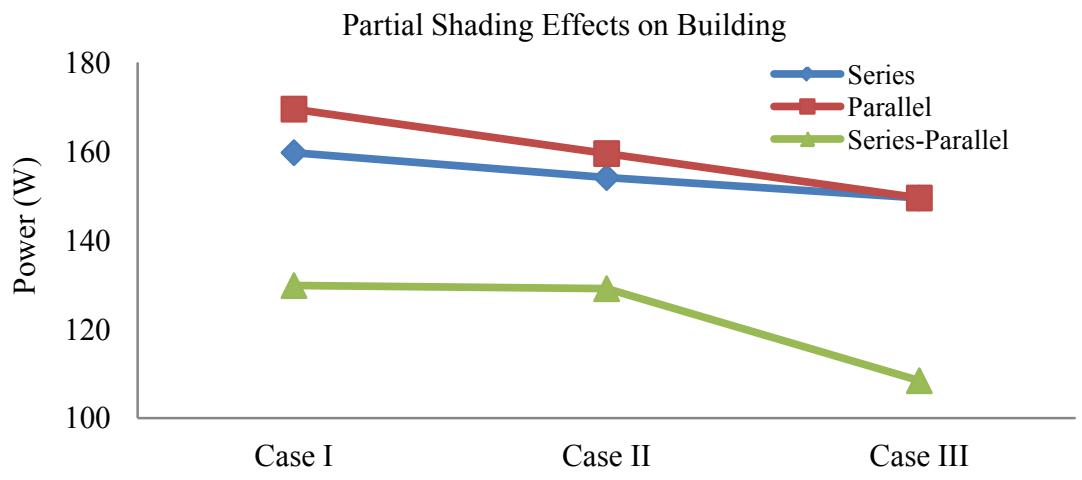

(b) Level of medium partial shading on building

Partial Shading Effects on Building

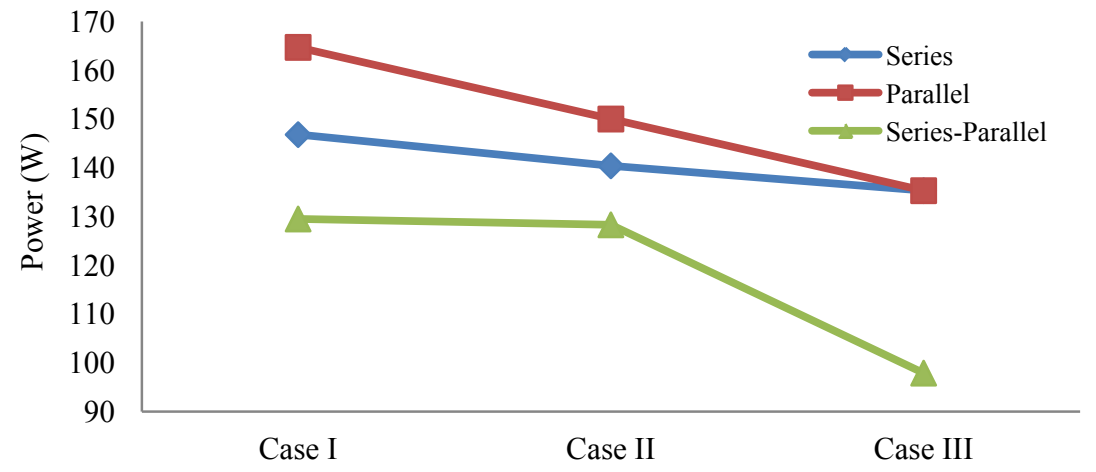

(c) Level of heavy partial shading on building

Figure 5. Comparision of power variations with respect to levels of partial shadings

Table 11. Scenario 2: Comparison of the various configurations under shading due to snow

\begin{tabular}{cccccc}
\hline Scenario & Case & Configuration & Max. Power (W) & Max. Current (A) & Max. Voltage (V) \\
\hline \multirow{3}{*}{ Shade due to snow } & All the modules are covered with & Series & 78.55 & 1.393 & 56.4 \\
& snow & Parallel & 78.55 & 4.178 & 18.8 \\
& & Series-Parallel & 56.08 & 1.427 & 39.31 \\
\hline
\end{tabular}


Table 12. Scenario 3: Comparison of the various configurations under shading due to cloud

\begin{tabular}{|c|c|c|c|c|c|}
\hline Scenario & Case & Configuration & Max. Power (W) & Max. Current (A) & Max. Voltage(V) \\
\hline \multirow{9}{*}{$\begin{array}{c}\text { Shade due to Cloud Cover(Heavy Cloud } \\
\text { Cover/Winter) }\end{array}$} & \multirow{3}{*}{ I } & Series & 146.8 & 2.725 & 53.87 \\
\hline & & Parallel & 156.3 & 8.714 & 17.94 \\
\hline & & Series-Parallel & 133.4 & 3.58 & 37.26 \\
\hline & \multirow{3}{*}{ II } & Series & 140.4 & 2.665 & 52.69 \\
\hline & & Parallel & 125.2 & 6.982 & 17.94 \\
\hline & & Series-Parallel & 125.2 & 3.491 & 35.87 \\
\hline & \multirow{3}{*}{ III } & Series & 135.3 & 2.628 & 51.46 \\
\hline & & Parallel & 135.3 & 7.243 & 17.96 \\
\hline & & Series-Parallel & 67.57 & 1.794 & 37.66 \\
\hline \multirow{9}{*}{$\begin{array}{c}\text { Shade due to Cloud Cover(Rainy } \\
\text { Season) }\end{array}$} & \multirow{3}{*}{ I } & Series & 113.2 & 3.503 & 32.3 \\
\hline & & Parallel & 120.9 & 7.374 & 16.39 \\
\hline & & Series-Parallel & 118.9 & 3.588 & 33.15 \\
\hline & \multirow{3}{*}{ II } & Series & 52.9 & 3.487 & 15.17 \\
\hline & & Parallel & 68.44 & 4.218 & 16.23 \\
\hline & & Series-Parallel & 55.36 & 3.498 & 15.83 \\
\hline & \multirow{3}{*}{ III } & Series & 16.45 & 0.3525 & 46.67 \\
\hline & & Parallel & 16.45 & 1.058 & 15.55 \\
\hline & & Series-Parallel & 11.84 & 0.3633 & 32.58 \\
\hline
\end{tabular}

It (Table 11) is observed that snow adversely affects the perfomance of the PV array. While the power ouptut can be as high as $180 \mathrm{~W}$ on a clear sunny day, it decreases to just about $80 \mathrm{~W}$ when facing snowy conditions. Under such conditions, series or parallel configurations will provide a better power output than the combination of series-parallel configuration.

Table 12 shows the results of the maximum power output for partial shading effects of clouds as they apply to the various PV module configurations in series, parallel, and series-parallel.

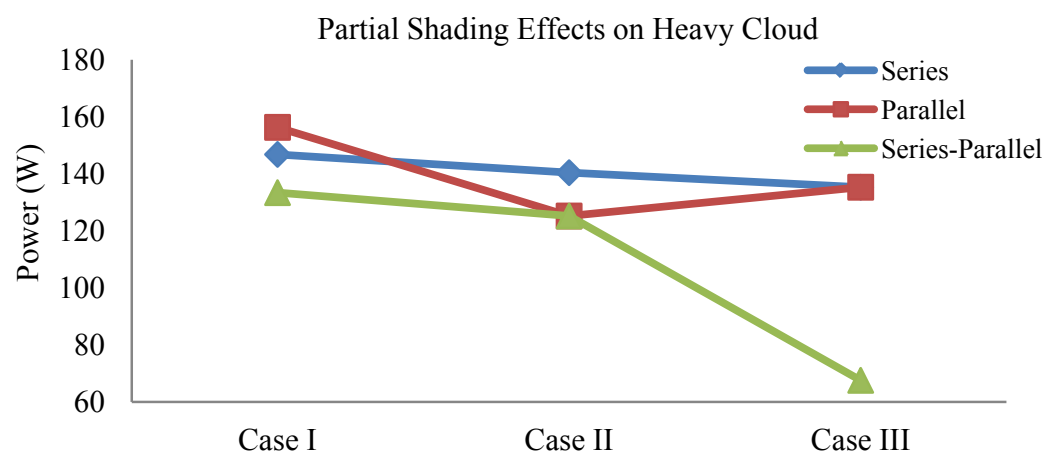

(a) Case of heavy cloud cover due to weather conditions

Partial Shading Effects on Rainy Cloud

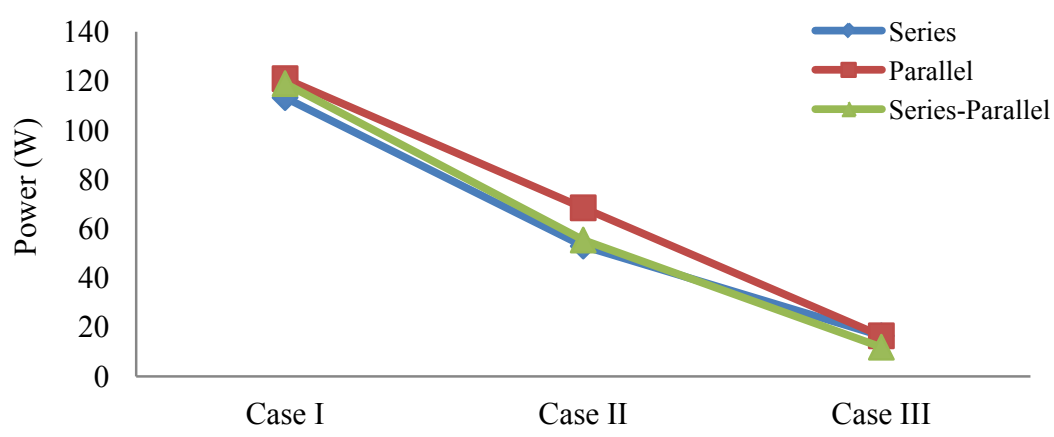

(b) Case of rainy clould cover

Figure 6. Considerations of cloud cover shaded by weather conditions and seasons 
It (Table 12) is observed that temperature can have a negative effect on power output. As the temperature increases, power decreases. Also, when cloud cover is present, irradition is reduced and, consequently, the power output drops. It is also observed that for both rainy and winter conditions, the parallel configuration gives the best performance outcome. Figure 6 shows variations of the power output with respect to the partial shadings caused by weather conditions and seasons in series, parallel, and series-parallel.

Table 13 shows the results of the maximum power output for partial shading effect of tree blockage as experienced by the various PV module configurations in series, parallel, and series-parallel.

It (Table 13) is observed that under shade conditions due to tree cover, parallel configurations give the best results. A maximum power of about $134 \mathrm{~W}$ is noticed against a value of $117 \mathrm{~W}$, which is an increase of about $14.5 \%$. Therefore, in a site where an array undergoes dense tree cover, parallel configuration should be preferred. Figure 7 shows variations of power output with respect to partial shadings caused by trees and seasons in series, parallel, and series-parallel.

Table 13. Comparison of the various configurations under shading due to trees

\begin{tabular}{|c|c|c|c|c|c|}
\hline Scenario & Case & Configuration & Max. Power (W) & Max. Current (A) & Max. Voltage (V) \\
\hline \multirow{9}{*}{$\begin{array}{l}\text { Scenario 4: } \\
\text { Shade due to Tree cover }\end{array}$} & \multirow{3}{*}{ I } & Series & 117.2 & 3.495 & 33.53 \\
\hline & & Parallel & 134.4 & 7.872 & 17.07 \\
\hline & & Series-Parallel & 125.8 & 3.593 & 35 \\
\hline & \multirow{3}{*}{ II } & Series & 54.92 & 3.497 & 15.78 \\
\hline & & Parallel & 89.33 & 5.259 & 16.99 \\
\hline & & Series-Parallel & 64.98 & 1.807 & 35.95 \\
\hline & \multirow{3}{*}{ III } & Series & 44.34 & 0.8786 & 50.47 \\
\hline & & Parallel & 44.34 & 2.637 & 16.82 \\
\hline & & Series-Parallel & 31.84 & 0.6036 & 35.24 \\
\hline
\end{tabular}

Partial Shading Effects on Trees

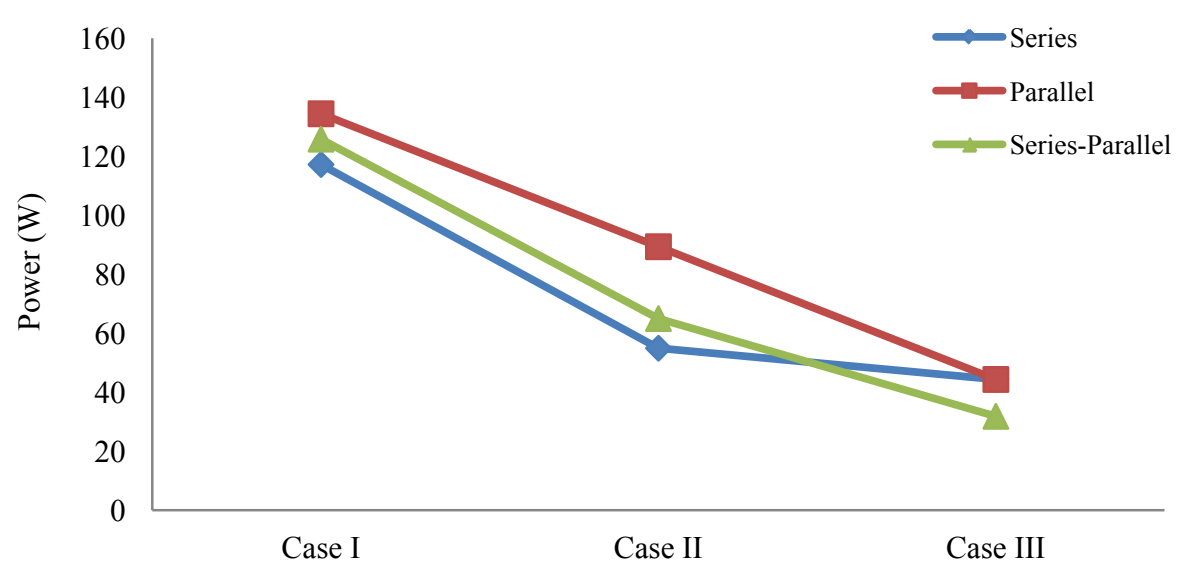

Figure 7. Considerations of tree cover shading

\section{Conclusion}

Analysis of various SPVA configurations with respect to environmental parameters has been investigated and more realistic models using MATLAB/Simulink have been developed. Two cases wherein cells in a PV module are connected in series and parallel were studied. The results confirmed that cells in a PV module, when connected in series, yield maximum power. Also, a Simulink model has been developed to simulate the behavior of PV modules with different configurations under variable meteorological conditions, in particular the impact of partial shading. In order to collect the maximum possible power output from partial shading caused by environmental conditions, it is recommended that the connection of a bypass diode in anti-parallel with a module or group of cells is required to avoid the stress on the shaded cells. This approach to PV module design would solve the problem of sensitivity of hot-spot as well as provide a higher power supply when compared to a solar PV module system without considering the configuration of bypass diode. The model developed has incorporated the effects of bypass diodes. An advantage of the presented simulation procedure is that the model developed here can be used for any array size and for any module by simply changing the specifications of the module used in the program. Furthermore, the input parameters (irradiance and temperature) can be changed, making possible the study of different shadow patterns in addition to temperature variations in particular solar modules. After analyzing the various configurations for different possible shading patterns for varied sizes, it is also observed that, in most cases, parallel configuration provides a higher amount of power when compared to the other configurations. Conversely, in some cases in which all the modules received the same insolation, series or a 
parallel configuration provided a higher power when compared to the other configurations.

\section{Nomenclature}

$I_{P V}, V_{P V}-$ Solar PV module Current (A) and Voltage (V) respectively

$I_{p h}$ - Photocurrent PV module (A)

$I_{d}$ - Diode reverse saturation current in the equivalent circuit $(\mu \mathrm{A})$

$R_{s}$ - Series resistance in the equivalent circuit of the module $(\mathrm{m} \Omega)$

$R_{s h}$ - Parallel resistance in the equivalent circuit of the module $(\Omega)$

$R_{L}$ - Load resistance

$\mathrm{D}$ - Diode used in the equivalent circuit

q - Electron charge $(=1.602 \times 10-19 \mathrm{C})$

$\mathrm{k}$ - Boltzman's constant $(=1.381 \times 10-23 \mathrm{~J} / \mathrm{K})$

$\mathrm{T}$ - Temperature (Kelvin)

$V_{T}$ - Thermal voltage (= nkT/q)

$\mathrm{G}$ - Insolation level (at reference condition $\mathrm{G}=1000$ $\left.W / m^{2}\right)$

$I_{S C} \& V_{O C}$ - Short circuit current and open circuit voltage of the module respectively

$V_{m p} \& I_{m p}$ - Maximum power point voltage and current respectively

$P_{m}$ - Maximum power

$\mathrm{Db}$ - Bypass diodes used in the series array configuration.

\section{References}

[1] W. Herrmann, W. Wiesner, and W. Vaassen, "Hot spot investigations on PV modules - new concepts for a test standard and consequences for module design with respect to bypass diodes," in Proceedings of the 26th IEEE Photovoltaic Specialists Conference, pp. 1129-1132, October 1997.

[2] N. D. Kaushika and N. K. Gautam, "Energy yield simulations of interconnected solar PV arrays," IEEE Transactions on Energy Conversion, vol. 18, no. 1, pp. 127-134, 2003.

[3] M. Klenk, S. Keller, L. Weber et al., "Investigation of the hotspot behaviour and formation in crystalline silicon Power cells, PV in Europe, From PV technology to energy solutions," in Proceedings of the International Conference, pp. 272-275, 2002.
[4] A. Woyte, J. Nijs, and R. Belmans, "Partial shadowing of photovoltaic arrays with different system configurations: literature review and field test results," Solar Energy, vol. 74, no. 3, pp. 217-233, 2003.

[5] R. Ramaprabha and B. L.Mathur, "A Comprehensive Review and Analysis of Solar Photovoltaic Array Configurations under Partial Shaded Conditions", 19 November 2011.

[6] E. K. Syafanuddin and T. Hiyama, "Polar coordinate fuzzy controller based real-time maximum-power point control of photovoltaic system", Renewable Energy, vol. 34, no. 12, pp. 2597-2606, (2009).

[7] C. S. Chin, P. Neelakantan, H. P. Yoong, K. K. Teo,"Fuzzy logic based MPPT for phorovoltic modules influenced by solar irradiance and cell temperature", Proceedings of 13th international conference on computer modeling and simulation, Cambridge, United Kingdom, pp. 376-381, (2011).

[8] C. S. Chin, P. Neelakantan, S. S. Yang, B. L. Chua, K. K. Teo,"Effect of Partially Shaded Conditions on Photovoltaic Array's Maximum Power Point Tracking", International Journal of Simulation Systems, Science \& Technology (IJSSST), vol. 12, no. 3, pp. 52-59, (2011)

[9] L. Gao, R. A. Dougal, S. Liu, and A. P. Iotova, "Parallelconnected solar PV system to address partial and rapidly fluctuating shadow conditions," IEEE Transactions on Industrial Electronics, vol. 56, no. 5, pp. 1548-1556, 2009.

[10] Mohammed Abdulazeez, Ires Iskender, "Simulation and Experimental study of Shading Effect on series and parallel connected PV", Gazi University, Ankara, Turkey.

[11] H. Patel and V. Agarwal," MATLAB-Based Modeling to Study the Effects of Partial Shading on PV Array Characteristics", IEEE Transactions on Energy Conversion, vol. 23, no. 1, pp. 302-310, (2008).

[12] Rifa J. El-Khozondar, Teuvo Suntio, "Matlab/Simulink Modeling to study the effect of partially shaded condition on Photovoltaic array's Maximum Power Point", May 2015

[13] Pendem, S.R. , S. Mikkili, “ Modeling, simulation and performance analysis of solar PV array configurations (Series, Series-Parallel and Honey-Comb) to extract maximum power under partial shading conditions", Energy Report, 4, pp 274-287, 2018

[14] Bellia, H., Youcef,R., Fatima, M., “ A detailed modeling of photovoltaic module using MATLAB", National Research Institute of Astronomy and Geophysics, pp 56-61, 2014

[15] Chris Deline, "Photovoltaic Shading Test bed for Module-Level Power Electronics", 2014.

[16] Roger French, "PV Module Performance under real world test conditions- A Data Analytics Approach", 2014.

[17] Paul Burgess, "Variation in light intensity at different latitudes and Seasons, effects of cloud cover, and the amounts of Direct and diffused light", September 2009.

[18] Gordon M Heisler "Effects of Individual trees on solar radiation climate of small buldings", 1985. 